Editor's Note: Disease Focus articles provide brief overviews of a neural disease or syndrome, emphasizing potential links to basic neural mechanisms. They are presented in the hope of helping researchers identify clinical implications of their research. For more information, see http://www.jneurosci.org/misc/ifa_minireviews.dtl.

\title{
Adult-Onset Autosomal Dominant Leukodystrophy: Linking Nuclear Envelope to Myelin
}

\author{
Shu-Ting Lin, Louis J. Ptáček, and Ying-Hui Fu \\ Department of Neurology, University of California, San Francisco, San Francisco, California 94158
}

\section{Introduction}

Adult-onset autosomal dominant leukodystrophy (ADLD) was first described for a large kindred with a progressive and fatal neurological white matter disorder in an American-Irish family (Eldridge et al., 1984). Subsequently, ADLD has been reported in many other ethnic groups including Japanese, Swedish, French, Italian, and French Canadian (Asahara et al., 1996; Marklund et al., 2006; Melberg et al., 2006; Meijer et al., 2008; Brussino et al., 2009, 2010). Clinically, ADLD is a progressive degenerative neurological disorder with pyramidal, cerebellar, and autonomic disturbances (Eldridge et al., 1984; Coffeen et al., 2000; Marklund et al., 2006; Melberg et al., 2006). The symptoms begin between the forth and sixth decades (mean age of $\sim 40$ years) of life with early presentation of autonomic symptoms, including bowel/bladder dysfunction, impotence in males, and orthostatic hypotension (Schwankhaus et al., 1988; Coffeen et al., 2000). Autonomic symptoms precede cerebellar signs (ataxia, dysmetria, nystagmus, and action tremors) and pyramidal abnormalities (spasticity and weakness of both upper and lower extremities). Mild cognitive, visual, and auditory abnormalities are also present in some cases. The peripheral nervous system is spared

\footnotetext{
Received Nov. 12, 2010; accepted Nov. 22, 2010.

We thank Dr. Ari Green at University of California, San Francisco for the assistance on the interpretation of MRI images.

Correspondence should be addressed to Ying-Hui Fu, Department of Neurology, University of California, San Francisco, 1550 Fourth Street, RH546, UCSFMission Bay, San Francisco, CA 94158. E-mail: ying-hui.fu@ucsf.edu. DOl:10.1523/JNEUROSCI.5994-10.2011

Copyright $\odot 2011$ the authors $\quad 0270-6474 / 11 / 311163-04 \$ 15.00 / 0$
}

(Schwankhaus et al., 1994). Upper motor neuron signs such as spastic paralysis, posterior column dysfunction, and extensor plantar responses are also common phenotypic characteristics (Coffeen et al., 2000). In addition to the clinical history and physical examination, magnetic resonance imaging (MRI) is the best method to diagnose ADLD. The MRI scans display diffuse, confluent and symmetric white matter involvement starting in the frontoparietal region, extending to the brainstem and cerebellar white matter (Fig. 1) (Bergui et al., 1997; Coffeen et al., 2000; Melberg et al., 2006). Periventricular white matter appears less affected than the adjacent white matter (Melberg et al., 2006). The diameter of the medulla oblongata is reduced in the coronal plane and the corpus callosum is atrophic (Schwankhaus et al., 1988; Melberg et al., 2006). Although spinal cord involvement has been reported in some cases (Sundblom et al., 2009), white matter changes are most significant in the brain. Neuropathological findings revealed white matter abnormalities in the frontoparietal and cerebellar white matter, whereas the cortex and subcortical U fiber showed no significant pathology in symptomatic ADLD patients (Schwankhaus et al., 1988; Coffeen et al., 2000; Melberg et al., 2006). Light microscopy showed vacuolated white matter with no significant loss of oligodendroglia accompanied by an absence of inflammatory changes and reactive astrocytosis (Coffeen et al., 2000; Melberg et al., 2006). Sparse astrocytes with intense reaction products (insulin-like growth factor-1 and vimentin) are accompanied by abnormally beaded or foreshortened morphology or abnormal thickening processes. Reduced numbers of Purkinje cells and slightly increased numbers of Bergmann cells in cerebellum are also noted (Melberg et al., 2006). Because no significant inflammatory infiltrates, activated microglia, or macrophages are present, this disorder does not appear to result from the direct autoimmune attack on myelin proteins that is present in multiple sclerosis. In addition, neuronal damage or axon loss is absent. Overall, preservation of oligodendroglia in the presence of demyelination and lacking or moderate astrogliosis under light microscopy are the unique features of ADLD (Coffeen et al., 2000; Melberg et al., 2006).

ADLD was found to be caused by duplication of $L M N B 1$ gene encoding lamin B1 (Padiath et al., 2006) (Fig. 2). Lamin B1 is a component of nuclear lamina which is a filamentous meshwork of proteins underlying the inner nuclear membrane. Nuclear lamina has been found to play dynamic roles in the organization and regulation of chromatin, transcription, DNA replication, DNA repair, and various epigenetic phenomena of euchromatin and heterochromatin transitions (Dechat et al., 2010). Mammalian cells have two major types of lamins, A and B types, and mutations in genes encoding the nuclear lamins can cause a wide range of human diseases, collectively called laminopathies (for review, see Worman and Bonne, 2007; Worman et al., 2010). Lamins anchor chromatin to the nuclear lamina and act as a scaffold for chromatin remodeling, and are critical for determining spatial organization 
of chromosomes in the nucleus (Vlcek and Foisner, 2007). Genomic regions that are tethered to the nuclear periphery were shown to be associated with reduced transcription of genes in the region (Finlan et al., 2008; Reddy et al., 2008). Specifically, lamin B1 was demonstrated to play a role in gene expression and chromosome position using cultured mammalian fibroblast cells lacking lamin B1 (Malhas et al., 2007). In addition, lamina-associated domains of lamin B1 are connected to genome regions with low expression levels, exhibiting lower levels of active chromatin, and enriched with silenced chromatin markers that indicate repressive chromatin organization (Pickersgill et al., 2006; Guelen et al., 2008; Towbin et al., 2009). The high-resolution genomenuclear lamina interaction maps of lamin B1 in pluripotent embryonic stem cells, multipotent precursor cells, and terminal differentiated cells revealed a dynamic interaction of nuclear lamina and genes in the genome according to cell type, differentiation steps, and gene expression levels correlating with subsequent repression or activation (Peric-Hupkes et al., 2010).

Overexpression of B-type lamins was shown to promote nuclear membrane growth and intranuclear membrane formation in amphibian oocytes, epithelium, and mammalian kidney cells in a CaaX motifdependent manner (Prüfert et al., 2004; Ralle et al., 2004). In agreement with these findings, ectopic overexpression of LMNB1 in neural and glial cells increased surface area of nuclear membrane and intranuclear aggregates (Lin and Fu, 2009). Increased expression of lamin $\mathrm{B} 1$ results in perturbations of inner nuclear membrane proteins, chromatin organization, and nuclear pore transport. Together, these changes lead to defects in oligodendroglia differentiation (Lin and $\mathrm{Fu}, 2009)$. It is possible that lamin B1 overexpression, through formation of abnormal intranuclear membranes, leads to the altered subcellular localization of nuclear envelope proteins and perturbed nuclear transport. In a primary culture system, lentivirus induces moderate overexpression of $L M N B 1$ in oligodendrocytes leading to drastic effects on myelin protein expression and defects of differentiation accompanied by minimal nuclear envelope growth/distortion compared with those found in established culture systems. These results suggest that genes required for myelin proteins and oligodendrocyte maturation are sensitive to changes in nuclear envelope. Indeed, the specific effects of $L M N B 1$ overexpression on gene transcription were confirmed by the repression of myelin-specific genes and the activation of GFAP transcrip-
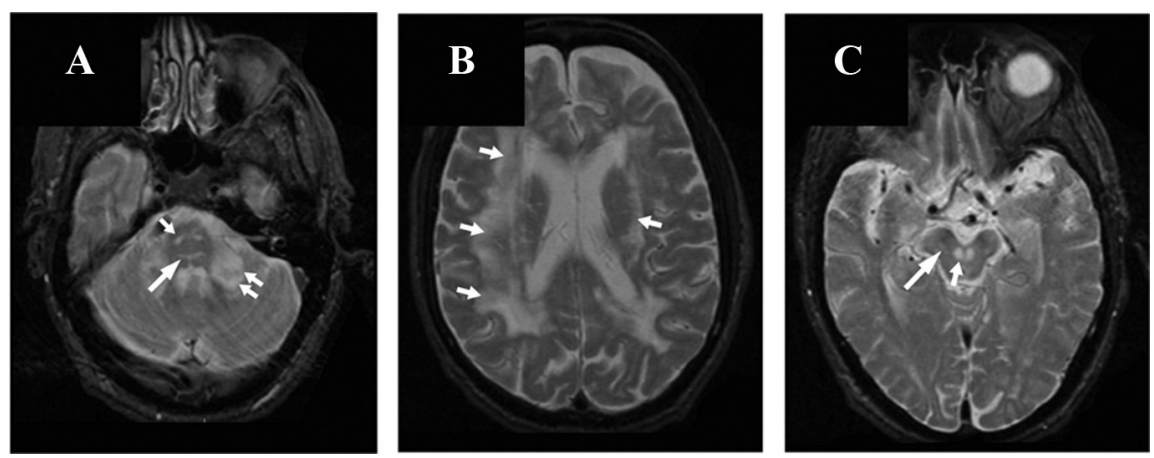

Figure 1. T2 weighted MRI showing characteristic white matter hyperintensities identified in patients with Lamin B1 mutations. These MRI abnormalities appear to be restricted to specific white matter tracts and accumulate through the course of disease. A, Transverse (axial) cross section through mid-pons at level of facial colliculus. Short arrow, Corticospinal and corticobulbar tracts (may include crossing pontine tracts); long arrow, medial lemniscus; double arrow, middle cerebellar peduncle (brachium pontis). $\boldsymbol{B}$, Transverse (axial) cross section through hemispheres at level of lateral ventricles. Three left side arrows, Superior longitudinal fasciculus; short arrow, cingulum. C, Transverse (axial) cross section through caudal midbrain below level of red nucleus. Short arrow, Crossing fibers of superior cerebellar peduncle (brachium conjunctivum); long arrow, medial lemniscus.
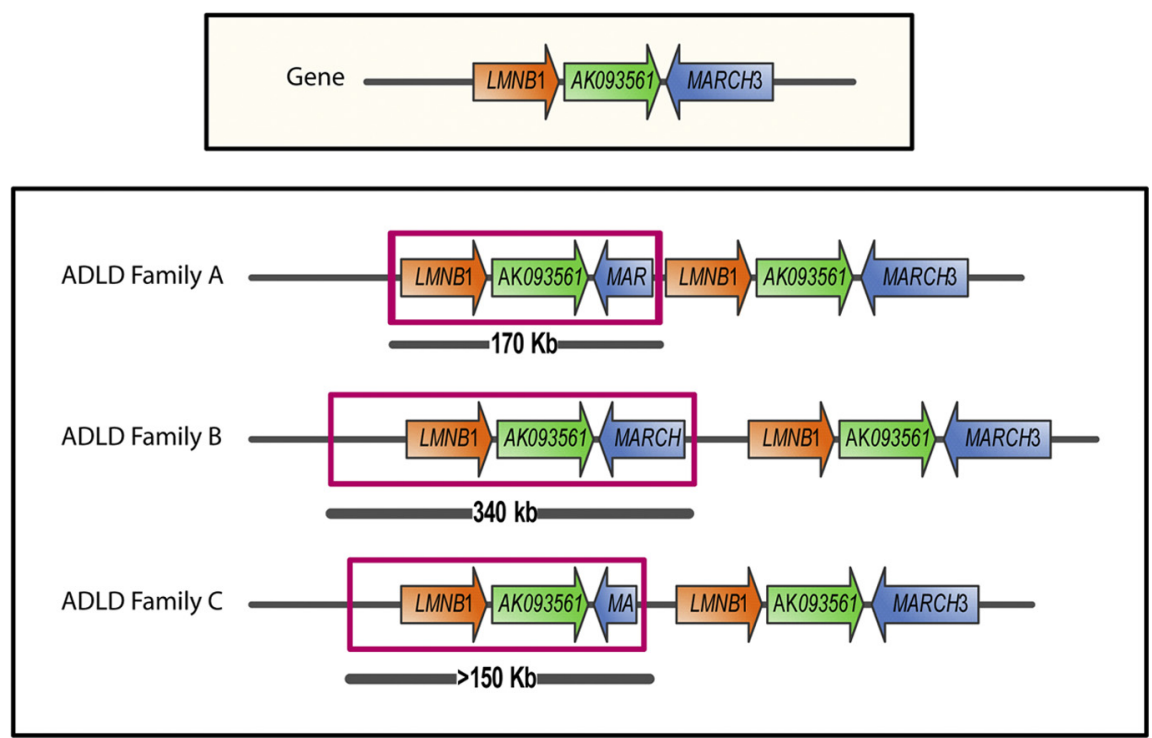

Figure 2. Schematic representation showing genomic structure of the size and extent of duplications in ADLD. Three families are shown according to size and extent of duplication of $L M N B 1$. Arrows indicate the direction of transcription and red boxes indicate the size and extent of duplications.

tion (Lin and $\mathrm{Fu}, 2009$ ). These results suggest that overexpression of $L M N B 1$ could disturb the unique gene expression patterns in individual CNS cell types and that phenotypes would only appear in certain cell types that are vulnerable to the transcriptional changes.

LMNB1 duplication is associated with the severe demyelinating phenotype in ADLD. This is the only disease of nuclear lamina linked to myelin (Padiath et al., 2006). Interestingly, duplications of PLP1 are one of the most common causes of demyelination in Pelizaeus-Merzbacher disease (Inoue et al., 1996; Inoue, 2005). Overexpression of the common myelin protein, proteolipid protein (PLP), causes endoplasmic reticulum stress leading to oli- godendrocyte demise (Bauer et al., 2002). Increased lamin B1 expression in neurons or glia causes lethality in Drosophila, while overexpression with an eye-specific driver causes a degenerative phenotype (Padiath et al., 2006). Gene trap insertion in mouse resulted in an allele encoding lamin B1 lacking the $\mathrm{C}$ terminus, and results in perinatal lethality due to lung and bone abnormalities (Vergnes et al., 2004). These results suggest that developmental processes in invertebrates and vertebrates are highly sensitive to the levels of lamin B1. Interestingly, lamin B1 in brain is developmentally regulated, with levels peaking at birth or postnatal day 1 , followed by a gradual decrease from postnatal day 1 to 10 months of age (Lin and Fu, 2009) (Fig. 3), and Lmnb1 mRNA levels are 


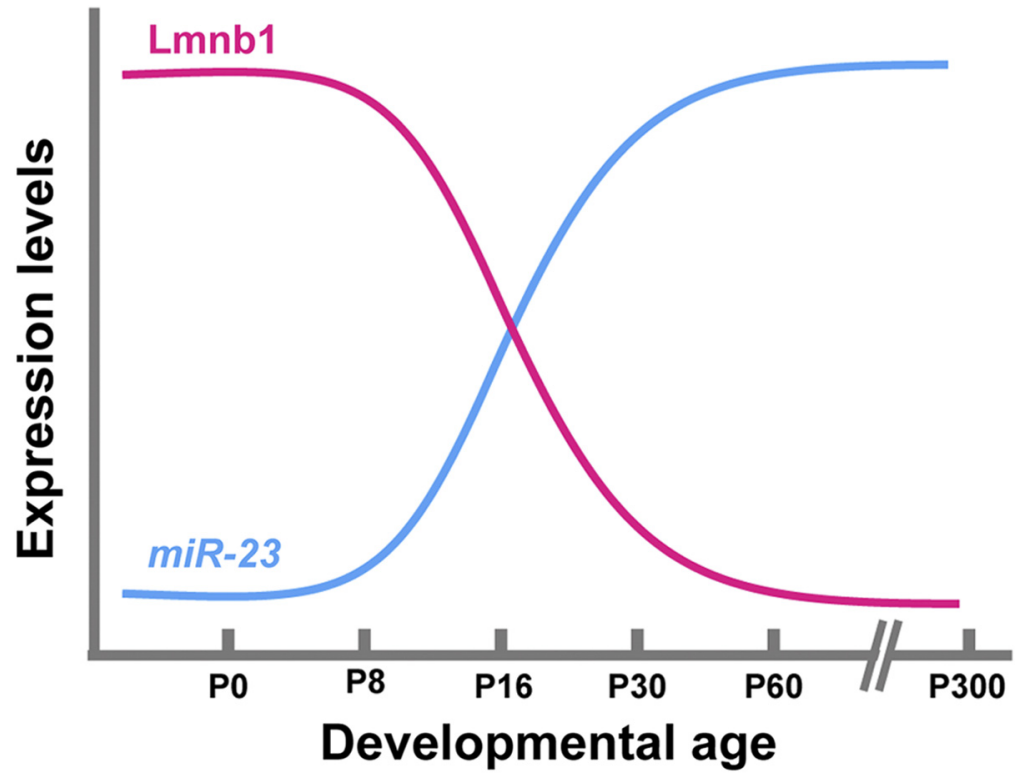

Figure 3. Level of miR-23 expression in the murine brain gradually increases with age in a pattern that is complementary to that of Lmnb1.

gradually downregulated during oligodendrocyte maturation (Dugas et al., 2006). All these results suggest a possible role for Lamin B1 in the regulation of oligodendrocyte development.

MicroRNAs (miRNAs) bind to mRNAs and target them for degradation or interfere with translation. There has been growing appreciation for miRNAs as essential regulators for biological processes, both in health and disease (Bartel, 2004; Stefani and Slack, 2008). miRNAs are initially generated from long hairpin-loop RNA precursors, which are consecutively processed to functional small noncoding RNAs $\sim 22$ nt by the ribonucleases, Drosha and Dicer, in the nucleus and cytoplasm before being assembled into an RNA-induced silencing complex (Bartel, 2004). In the developing CNS, many miRNAs show a distinct expression pattern (Landgraf et al., 2007), supporting the idea that they may play important roles during mammalian brain development, particularly for cell type differentiation in the CNS (Johnston and Hobert, 2003). In addition, expression levels of miRNAs in oligodendroglia are altered according to their differentiation stages, indicating a possible role in switching between migratory, proliferating, and myelinating oligodendrocytes (Lau et al., 2008; Budde et al., 2010; Dugas et al., 2010; Nave, 2010; Zhao et al., 2010). Dicer ablation in oligodendroglia at postdevelopmental stages results in a neurodegenerative phenotype including demyelination, inflammation, and axon loss (Shin et al., 2009), suggesting that miRNAs are also im- portant for myelin maintenance at later developmental stages. In the presence of excess $m i R-23$ in cell cultures, a greater proportion of cells express mature markers of oligodendrocytes that are paralleled by multipolar morphological appearance with increased levels of mature myelin proteins, indicating that $m i R-23$ can enhance oligodendrogenesis. In contrast, excessive lamin B1 leads to lower numbers of cells expressing mature markers with reduced levels of mature myelin proteins, suggesting defective differentiation of oligodendrocytes. Importantly, the adverse effect of lamin B1 on oligodendrocyte cells can be abrogated by $m i R-23$ as a negative regulator of lamin $\mathrm{B} 1$ ( $\mathrm{Lin}$ and $\mathrm{Fu}$, 2009). Interestingly, the developmental expression pattern of $m i R-23$ is reciprocal to that of the lamin B1 (Fig 3). The relevance of these in vitro findings to the in vivo situation is supported by the observation of reduced levels of oligodendrocyte- and myelinspecific proteins at a molecular level in ADLD brain tissues. It is possible that miR-23 can also enhance oligodendrocyte development through other lamin B1-independent pathways. In this case, excessive lamin B1 production in the cells may sequester miR-23 during maturation, thereby further adding to the deteriorating myelin loss from lamin B1 overexpression in the CNS.

Myelin generation and healthy myelin maintenance are complex processes that require delicate orchestration of a large number of factors and pathways. However, our understanding of these processes remains incomplete. The involvement of nuclear lamina and miRNAs in myelin regulation has only recently been discovered. Identification of upstream enhancer/repressor elements that can modulate miRNA expression and additional downstream effectors of lamin B1 and miR-23 may provide new insight into the mechanisms of oligodendrocyte development, myelin formation, and maintenance. A mouse model overexpressing lamin B1 and mimicking the human ADLD condition will be a critical resource for further investigations in vivo. Growing understanding of novel pathways critical for myelin regulation will provide novel targets to screen for molecules/compounds for treatment of disorders of myelin. In vivo and in vitro studies exploring mechanisms that link miRNAs and lamins to oligodendroglia maturation and myelin maintenance will certainly extend our knowledge into molecular mechanisms of glia development and myelin synthesis. Ultimately, such advances will hopefully lead to better treatments for ADLD and other myelin disorders.

\section{References}

Asahara H, Yoshimura T, Sada S, Furuya H, Kobayashi T (1996) [A Japanese family with probably autosomal dominant adult-onset leukodystrophy]. Rinsho Shinkeigaku 36:968972.

Bartel DP (2004) MicroRNAs: genomics, biogenesis, mechanism, and function. Cell 116:281-297.

Bauer J, Bradl M, Klein M, Leisser M, Deckwerth TL, Wekerle H, Lassmann H (2002) Endoplasmic reticulum stress in PLP-overexpressing transgenic rats: gray matter oligodendrocytes are more vulnerable than white matter oligodendrocytes. J Neuropathol Exp Neurol 61:12-22.

Bergui M, Bradac GB, Leombruni S, Vaula G, Quattrocolo G (1997) MRI and CT in an autosomal-dominant, adult-onset leukodystrophy. Neuroradiology 39:423-426.

Brussino A, Vaula G, Cagnoli C, Pradotto L, Daniele D, Di Gregorio E, Barberis M, Arduino C, Squadrone S, Abete MC, Migone N, Calabrese O, Brusco A (2009) A novel family with lamin B1 duplication associated with adult-onset leucoencephalopathy. J Neurol Neurosurg Psychiatry 80:237-240.

Brussino A, Vaula G, Cagnoli C, Panza E, Seri M, Di Gregorio E, Scappaticci S, Camanini S, Daniele D, Bradac GB, Pinessi L, Cavalieri S, Grosso E, Migone N, Brusco A (2010) A family with autosomal dominant leukodystrophy linked to 5q23.2-q23.3 without lamin B1 mutations. Eur J Neurol 17:541-549.

Budde H, Schmitt S, Fitzner D, Opitz L, SalinasRiester G, Simons M (2010) Control of oligodendroglial cell number by the miR-17-92 cluster. Development 137:2127-2132.

Coffeen CM, McKenna CE, Koeppen AH, Plaster NM, Maragakis N, Mihalopoulos J, Schwankhaus JD, Flanigan KM, Gregg RG, Ptácek LJ, Fu YH (2000) Genetic localization of an autosomal 
dominant leukodystrophy mimicking chronic progressive multiple sclerosis to chromosome 5q31. Hum Mol Genet 9:787-793.

Dechat T, Adam SA, Taimen P, Shimi T, Goldman RD (2010) Nuclear Lamins. Cold Spring Harb Perspect Biol 2:a000547.

Dugas JC, Tai YC, Speed TP, Ngai J, Barres BA (2006) Functional genomic analysis of oligodendrocyte differentiation. J Neurosci 26:1096710983.

Dugas JC, Cuellar TL, Scholze A, Ason B, Ibrahim A, Emery B, Zamanian JL, Foo LC, McManus MT, Barres BA (2010) Dicer1 and miR-219 Are required for normal oligodendrocyte differentiation and myelination. Neuron 65:597611.

Eldridge R, Anayiotos CP, Schlesinger S, Cowen D, Bever C, Patronas N, McFarland H (1984) Hereditary adult-onset leukodystrophy simulating chronic progressive multiple sclerosis. N Engl J Med 311:948-953.

Finlan LE, Sproul D, Thomson I, Boyle S, Kerr E, Perry P, Ylstra B, Chubb JR, Bickmore WA (2008) Recruitment to the nuclear periphery can alter expression of genes in human cells. PLoS Genet 4:e1000039.

Guelen L, Pagie L, Brasset E, Meuleman W, Faza MB, Talhout W, Eussen BH, de Klein A, Wessels L, de Laat W, van Steensel B (2008) Domain organization of human chromosomes revealed by mapping of nuclear lamina interactions. Nature 453:948-951.

Inoue K (2005) PLP1-related inherited dysmyelinating disorders: Pelizaeus-Merzbacher disease and spastic paraplegia type 2. Neurogenetics 6:1-16.

Inoue $\mathrm{K}$, Osaka H, Sugiyama N, Kawanishi C, Onishi H, Nezu A, Kimura K, Yamada Y, Kosaka K (1996) A duplicated PLP gene causing Pelizaeus-Merzbacher disease detected by comparative multiplex PCR. Am J Hum Genet 59:32-39.

Johnston RJ, Hobert O (2003) A microRNA controlling left/right neuronal asymmetry in Caenorhabditis elegans. Nature 426:845-849.

Landgraf P, Rusu M, Sheridan R, Sewer A, Iovino N, Aravin A, Pfeffer S, Rice A, Kamphorst AO, Landthaler M, Lin C, Socci ND, Hermida L, Fulci V, Chiaretti S, Foà R, Schliwka J, Fuchs U, Novosel A, Müller RU, et al (2007) A mammalian microRNA expression atlas based on small RNA library sequencing. Cell 129: 1401-1414.

Lau P, Verrier JD, Nielsen JA, Johnson KR, Not- terpek L, Hudson LD (2008) Identification of dynamically regulated microRNA and mRNA networks in developing oligodendrocytes. J Neurosci 28:11720-11730.

Lin ST, Fu YH (2009) miR-23 regulation of lamin B1 is crucial for oligodendrocyte development and myelination. Dis Model Mech 2:178-188.

Malhas A, Lee CF, Sanders R, Saunders NJ, Vaux DJ (2007) Defects in lamin B1 expression or processing affect interphase chromosome position and gene expression. J Cell Biol 176:593-603.

Marklund L, Melin M, Melberg A, Giedraitis V, Dahl N (2006) Adult-onset autosomal dominant leukodystrophy with autonomic symptoms restricted to $1.5 \mathrm{Mbp}$ on chromosome 5q23. Am J Med Genet B Neuropsychiatr Genet 141B:608-614.

Meijer IA, Simoes-Lopes AA, Laurent S, Katz T, St-Onge J, Verlaan DJ, Dupré N, Thibault M, Mathurin J, Bouchard JP, Rouleau GA (2008) A novel duplication confirms the involvement of 5q23.2 in autosomal dominant leukodystrophy. Arch Neurol 65:1496-1501.

Melberg A, Hallberg L, Kalimo H, Raininko R (2006) MR characteristics and neuropathology in adult-onset autosomal dominant leukodystrophy with autonomic symptoms. AJNR Am J Neuroradiol 27:904-911.

Nave KA (2010) Oligodendrocytes and the "micro brake" of progenitor cell proliferation. Neuron 65:577-579.

Padiath QS, Saigoh K, Schiffmann R, Asahara H, Yamada T, Koeppen A, Hogan K, Ptácek LJ, Fu YH (2006) Lamin B1 duplications cause autosomal dominant leukodystrophy. Nat Genet 38:1114-1123.

Peric-Hupkes D, Meuleman W, Pagie L, Bruggeman SW, Solovei I, Brugman W, Gräf S, Flicek P, Kerkhoven RM, van Lohuizen M, Reinders M, Wessels L, van Steensel B (2010) Molecular maps of the reorganization of genome-nuclear lamina interactions during differentiation. Mol Cell 38:603-613.

Pickersgill H, Kalverda B, de Wit E, Talhout W, Fornerod M, van Steensel B (2006) Characterization of the Drosophila melanogaster genome at the nuclear lamina. Nat Genet 38:1005-1014.

Prüfert K, Vogel A, Krohne G (2004) The lamin CxxM motif promotes nuclear membrane growth. J Cell Sci 117:6105-6116.

Ralle T, Grund C, Franke WW, Stick R (2004)
Intranuclear membrane structure formations by CaaX-containing nuclear proteins. J Cell Sci 117:6095-6104.

Reddy KL, Zullo JM, Bertolino E, Singh H (2008) Transcriptional repression mediated by repositioning of genes to the nuclear lamina. Nature 452:243-247.

Schwankhaus JD, Patronas N, Dorwart R, Eldridge R, Schlesinger S, McFarland $\mathrm{H}$ (1988) Computed tomography and magnetic resonance imaging in adult-onset leukodystrophy. Arch Neurol 45:1004-1008.

Schwankhaus JD, Katz DA, Eldridge R, Schlesinger S, McFarland H (1994) Clinical and pathological features of an autosomal dominant, adult-onset leukodystrophy simulating chronic progressive multiple sclerosis. Arch Neurol 51: 757-766.

Shin D, Shin JY, McManus MT, Ptácek LJ, Fu YH (2009) Dicer ablation in oligodendrocytes provokes neuronal impairment in mice. Ann Neurol 66:843-857.

Stefani G, Slack FJ (2008) Small non-coding RNAs in animal development. Nat Rev Mol Cell Biol 9:219-230.

Sundblom J, Melberg A, Kalimo H, Smits A, Raininko R (2009) MR imaging characteristics and neuropathology of the spinal cord in adult-onset autosomal dominant leukodystrophy with autonomic symptoms. AJNR Am J Neuroradiol 30:328-335.

Towbin BD, Meister P, Gasser SM (2009) The nuclear envelope- a scaffold for silencing? Curr Opin Genet Dev 19:180-186.

Vergnes L, Péterfy M, Bergo MO, Young SG, Reue $\mathrm{K}$ (2004) Lamin B1 is required for mouse development and nuclear integrity. Proc Natl Acad Sci U S A 101:10428-10433.

Vlcek S, Foisner R (2007) Lamins and laminassociated proteins in aging and disease. Curr Opin Cell Biol 19:298-304.

Worman HJ, Bonne G (2007) "Laminopathies": a wide spectrum of human diseases. Exp Cell Res 313:2121-2133.

Worman HJ, Ostlund C, Wang Y (2010) Diseases of the nuclear envelope. Cold Spring Harb Perspect Biol 2:a000760.

Zhao X, He X, Han X, Yu Y, Ye F, Chen Y, Hoang T, Xu X, Mi QS, Xin M, Wang F, Appel B, Lu QR (2010) MicroRNA-mediated control of oligodendrocyte differentiation. Neuron 65:612626. 